NASA Technical Memorandum 87295

\title{
Simplified Composite Micromechanics for Predicting Microstresses
}

Christos C. Chamis

Lewis Research Center

Cleveland, Ohio

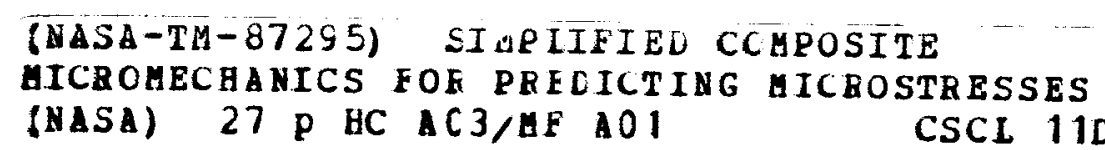

CSCL 11D

Prepared for the 41 st Annual Conference of the Society of the Plastics Industry (SPI) Reinforced Plastics/Composites Institute Atlanta, Georgia, January 27-31, 1986

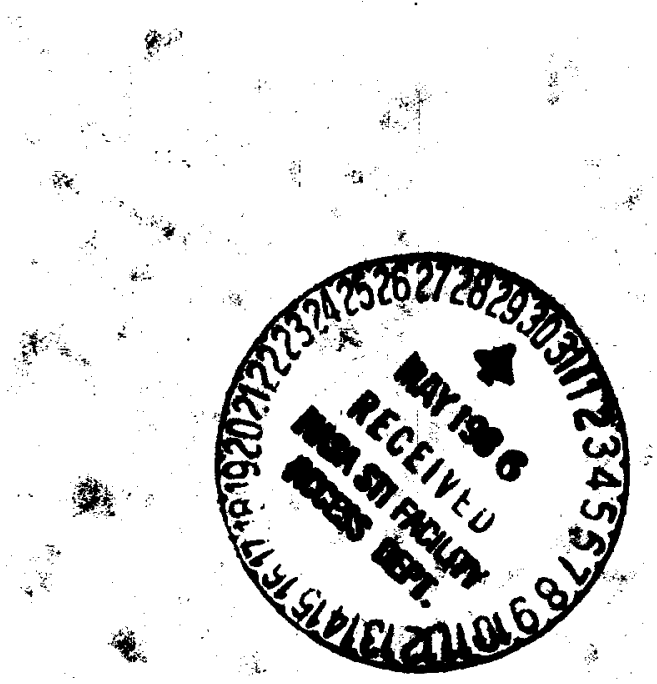


CONTENTS

Page

SUMMARY . . . . . . . . . . . . . . . . . . . . . . . . 1

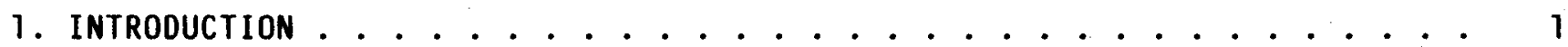

2. DEFINITIONS AND CONSTITUENT MATERIALS . . . . . . . . . . . . . . 2

3. PLY MICROSTRESSES DUE TO PLY LONGITUdINAL STRESS $\left(\sigma_{\ell 11}\right)$. . . . . . . . . 3

4. Ply microstresses due to Ply tRansverse StresS $\left(\sigma_{\ell 22}\right)$. . . . . . . . . . 4

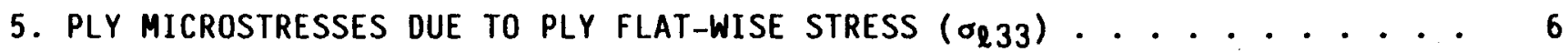

6. PLY MICROSTRESSES DUE TO PLY INTRAPLY SHEAR STRESS $\left(\sigma_{\ell 12}\right.$ or $\left.\sigma_{\ell} 13\right)$. . . . 6

7. PLY MICROSTRESSES DUE TO PLY THROUGH-THE-THICKNESS SHEAR STRESS $\left(\sigma_{\ell 23}\right) \cdot .8$

8. Ply microstresses due to temperature Change $\left(\Delta T_{\ell}\right)$. . . . . . . . . . . . . 9

9. Ply MICROSTRESSES DUE TO MOISTURE ChANGE $\left(M_{\ell}\right)$. . . . . . . . . . . . 11

10. DISCUSSION . . . . . . . . . . . . . . . . . . . . . . . . 13

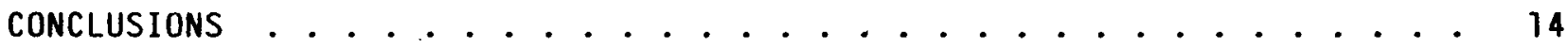

APPENDIX - SYMBOLS . . . . . . . . . . . . . . . . . . 15

REFERENCES ................................ 18 


\title{
SIMPLIFIED COMPOSITE MICROMECHANICS FOR PREDICTING MICROSTRESSES
}

\author{
Christos C. Chamis* \\ National Aeronautics and Space Administration \\ Lewis Research Center \\ Cleveland, Ohio 44135
}

\section{SUMMARY}

A unified set of composite micromechanics equations is summarized and described. This unified set is for predicting the ply microstresses when the ply stresses are known. The set consists of equations of simple form for predicting three-dimensional stresses (six each) in the matrix, fiber, and interface. Several numerical examples are included to fllustrate use and computational effectiveness of the equations in this unified set. Numerical results from these examples are discussed with respect to their significance on microcrack formation and, therefore, damage initiation in fiber composites.

\section{INTRODUCTION}

The stresses (strains) (type and magnitude) in the matrix, in the fiber, and at the fiber/matrix interface, determine the structural integrity and/or the damage tolerance of fiber composites. These stresses are normally called microstresses in the fiber composites community. Microstresses are present in fiber composites from the instant the composite starts curing. other microstresses are induced by the applied loads and/or moisture pick-up. In general, there are three kinds of microstresses: hygral (moisture), thermal, and mechanical. These microstresses vary in magnitude, sense (tension and compression), and type (normal and shear). At each point in the fiber, in the matrix, and/or at the interface there generally are six components of stress (strain) - three normal and three shear.

Determination of the magnitude, sense and type of microstresses requires highly intricate experiments (such as photoelasticity) and/or very detailed three-dimensional finite element analysis. In few limited cases, the magnitude of transverse and shear microstresses can be estimated by simple theoretical expressions. These simple expressions are used to determine the stress (strain) magnification between fibers and, therefore, obtain an assessment of possible microcracking and interfaclal disbonds. Recent research at NASA Lewis focused on deriving simple theoretical expressions for all six microstresses in the fibers, in the matrix, and at the interface. As a result, a unified set of simplified micromechanics equations was developed to predict the fiber composite microstresses. The objective of this report is to describe this unified set and illustrate its significance through appropriate numerical examples.

*Senior Research Engineer, Aerospace Structures/Composites. 


\section{DEFINITIONS AND CONSTITUENT MATERIALS}

The branch of composite mechanics which provides the formal structure whereby the ply microstresses are related to the ply stresses and to the ply constituent materials is called composite micromechanics. Composite micromechanics for predicting ply microstresses is defined concisely in figure 1 which also identifies the required input and the resulting output. The input consists of: (1) constituent materials and their respective properties, (2) ply geometric configuration, (3) fabrication process variables, and (4) ply stresses. The output consists of: (1) ply microstress influence coefficients, (2) fiber stresses, (3) interfacial stresses, (4) interfiber matrix stresses, (5) intermatrix matrix stresses, (6) fracture checks for local fiber, interfacial bond, and local matrix, and (7) ply microcracking assessment.

The formal structure of composite micromechanics (concepts, math-models, and equations) for predicting ply microstresses is derived based on assumptions which are consistent with (1) the physical situation and (2) the fundamental principles of solid mechanics. These assumptions are: (1) the ply resists primary loads by in-plane action as depicted schematically in figure 2 , (2) the ply resists secondary loads by through-the-thickness (interlaminar) action, and (3) the ply and its constituents behave linearly elastic, or nearly so, to fracture as depicted schematically in figure 3 . Though the principles of solid mechanics can be used with various levels of sophistication, the elementary mechanics-of-materials theory was used in deriving the equations summarized herein because: (1) it leads to explicit equations of simple form and (2) it is consistent with the simplified composite micromechanics equations used to predict ply hygrothermomechanical properties (ref. 1) and ply strengths (ref. 2).

The ply microstresses are determined through composite stress progressive decomposition as depicted schematically in figure 4 . The ply stress can be determined from composite stresses as described in references 4 to 7 . The composite stresses $\left(\sigma_{c}\right)$ are defined in the composite structural coordinate reference axes $(x, y, z)$. The ply stresses $\left(\sigma_{\ell}\right)$ are defined in the ply material coordinate reference axes (refs. $1,2,3$ ). The ply microstresses are defined in a representative intraply region in the ply material coordinate reference axes in two subregions, interfiber (B) and intermatrix ( $A$ ), as shown at the lower left in figure 4 and, in more detail in figure 5. (B) The interfiber microstresses in the matrix in subregion (B) are denoted by $\sigma_{m}(B)$ (fig. 5 ) and those in the fiber by $\sigma_{f}^{(B)}$ (fig. 5). The intermatrix micro-stresses in the matrix in subregion (A) are denoted by $\sigma_{m}^{(A)}(\mathrm{fig} .5)$. The interfacial microstresses are assumed to be: (1) "zero" in subregion (A), (2) the same as those in the interfiber matrix in subregion (B) but denoted by $\sigma_{i}^{(B)}$, and (3) combinations of subregions (A) and (B) identified as subregion (C) in figure 6 and denoted by $\sigma_{i}^{(C)} N, S^{\circ}$

Typical properties of select fibers, and matrices, and composites are respectively summarized in tables 1 and 2 . Properties from these tables are used to determine ply microstresses as described in the illustrative examples. 


\section{PLY MICROSTRESSES DUE TO PLY LONGITUDINAL STRESS $\left(\sigma_{\ell 11}\right)$}

The equations to predict stresses in the constituents due to a uniaxial longitudinal ply stress are summarized in figure 7 . The schematics in the figure define the notation in the equations and their respective subregions. The longitudinal matrix microstresses are assumed to be the same in both subregions $(A)$ and $(B)$. The longitudinal microstresses depend on relative constituent and ply moduli while the transverse microstresses also depend on constituent and ply Poisson's ratios and explicitely on the fiber volume ratio.

In order to use the ply microstress equations in figure 7 , we need two fiber properties $\left(E_{f} 11\right.$ and $\left.v_{f} 12\right)$, two matrix properties ( $E_{m}$ and $\left.v_{m}\right)$, two ply properties $\left(E_{\ell 11}\right.$, v $\left.v_{\ell 12}\right)$, the fiber volume ratio $\left(k_{f}\right)$ and the $p l y$ longitudinal stress ( $\left.\sigma_{\ell} 11\right)$. The fiber and matrix properties are obtained from tables 1 and 2 . The ply properties are calculated from the equations listed at the bottom of figure 7. The following examples illustrate use of the equations.

Example 3.1.: Determine the constituent stresses (ply microstresses) in an AS/IMHS ply with 0.6 fiber volume ratio, assuming: (a) $200 \mathrm{ksi}$ tensile ply stress, (b) $180 \mathrm{ksi}$ compressive ply stress and (c) $\sigma_{\ell 23}=0$. These ply stresses correspond to ply uniaxial fracture stresses.

Solution: The required computations are expedited by proceeding as follows: (1) select respective constituent material properties from tables 1 and 2; (2) calculate ply properties from the equations in figure 7; (3) substitute these properties in the microstress equations together with the given fiber volume ratio and ply stress(es); (4) calculate the microstresses from the appropriate equations in figures 7 and 6 (for interfacial bond); and (5) summarize the results. For this example, the constituent material and piy properties are:

\begin{tabular}{lrrr} 
Property, units & \multicolumn{3}{c}{ Property type } \\
& Fiber & Matrix & Ply \\
& & & \\
Modulus, mpsi & 31.0 & 0.5 & 18.8 \\
Poisson's ratio & 0.20 & 0.35 & 0.26
\end{tabular}

The corresponding ply microstresses (rounded to one decimal place) are:

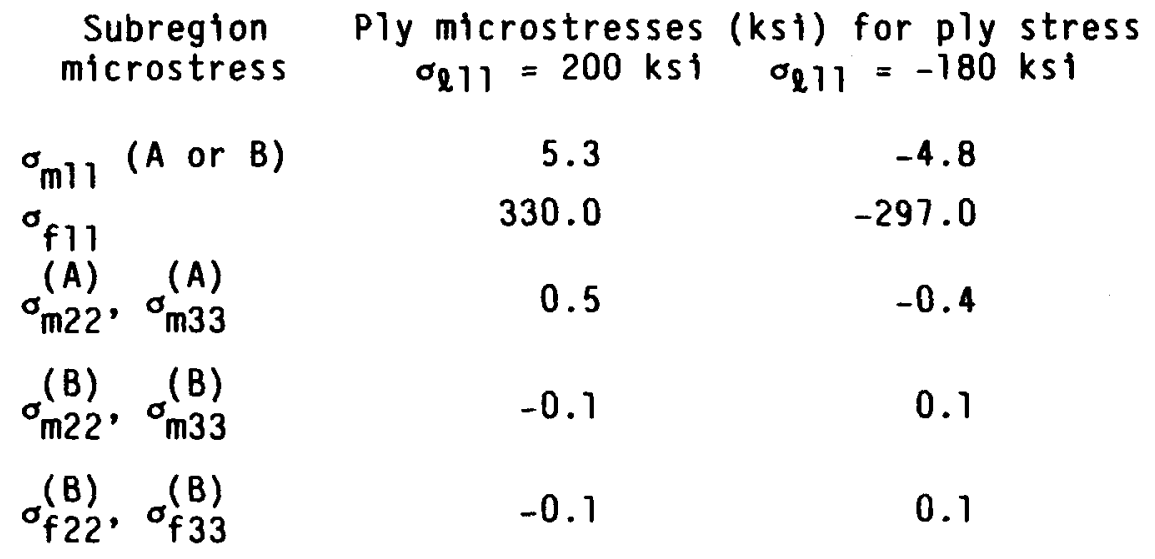




\begin{tabular}{|c|c|c|}
\hline $\begin{array}{l}\text { Subregion } \\
\text { microstress }\end{array}$ & $\begin{array}{l}\text { Ply microstresses } \\
\sigma_{\ell 11}=200 \mathrm{ks} 1\end{array}$ & $\begin{array}{l}\text { (ksi) for ply stress } \\
\sigma_{\ell l 1}=-180 \mathrm{ksi}\end{array}$ \\
\hline$\sigma_{122}^{(B)}, \sigma_{133}^{(B)}$ & -0.1 & 0.1 \\
\hline$\sigma_{i N}^{(C)}$ & 0.6 & -0.4 \\
\hline$\sigma_{\text {is }}^{(C)}$ & 0 & 0 \\
\hline
\end{tabular}

Examining the magnitudes of the microstresses, the following are observed: (1) the longitudinal ply stresses are primarily resisted by the fibers as expected; (2) The stresses in the matrix in subregions (A) and (B) are negligible compared to matrix strength ( $15 \mathrm{ksi}$ tensile, $35 \mathrm{ksi}$ compressive in table 2); (3) ply longitudinal stress induces microstresses in subregions (A) and (B) of opposite sign; and (4) the interfacial bond stress in subregion (C) may be of sufficient tensile magnitude to cause interfacial disbonding. (The interfacial tensile bonding strength is typically estimated to be about $1.0 \mathrm{ksi}$ ). It may be concluded, therefore, that longitudinal ply stresses will generally induce microfractures associated with (in the order of most probable occurrence): (1) fiber fractures, (2) interfacial disbonds, and (3) matrix fracture.

\section{PLy microstresses dUe to PLy tRANSVERSE StRESS $\left(\sigma_{\ell 22}\right)$}

The equations to predict stresses in the constituents due to a transverse ply stress are summarized in figure 8 . The schematics in the figure depict the notation in the equations and their respective subregions. The longitudinal microstresses in the matrix are the same in both subregions (A) and (B). These microstresses depend on relative constituent/ply Poisson's ratios and moduli. The transverse microstresses depend on relative local/ply moduli (ply moduli defined at the bottom of the figure). These microstresses also depend on the constituent properties and the fiber volume ratio through the piy moduli and Poisson's ratio.

In order to use the ply microstress equations in figure 8 , we need four fiber properties $\left(E_{f 11}, E_{f 22}, v_{f 12}\right.$, and $\left.v_{f 23}\right)$, two matrix properties ( $E_{m}$ and $\left.v_{m}\right)$, four ply properties $\left(E_{\ell 11}, E_{\ell 22}, v_{\ell 12}\right.$, and $\left.v_{\ell 23}\right)$, the fiber volume ratio $(\mathrm{kf})$, and the ply transverse stress (al22). The fiber and matrix properties are obtained from tables 1 and 2. The ply properties are calculated from the equations shown at the bottom of figures 7 and 8 . The ply fiber volume ratio and the ply transverse stress are assumed known. The following example fllustrates use of these equations.

Example 4.1: Determine the constituent stresses (ply microstresses) in an AS/IMHS ply with 0.6 fiber volume ratio assuming: (a) $7 \mathrm{ksi}$ tensile trans verse ply stress, (b) $35 \mathrm{ksi}$ compressive transverse ply stress and $(\lambda) \sigma_{\ell 23}=0$. These ply transverse stresses are about equal to corresponding uniaxial ply fracture stresses.

Solution: The required computations are expedited by proceeding as follows: (1) select respective constituent material properties from tables 1 and 2 ; (2) calculate ply properties from the equations at the bottom of figures 7 and 8 ; (3) substitute these properties in the microstress equations together with the ply transverse stress; (4) calculate the microstresses from 
the appropriate equations in figures 8 and 6 (for interfacial bond); and (5) summarize the results. For this example, the constituent material and ply properties are:

\begin{tabular}{crcc} 
Property, units & \multicolumn{3}{c}{ Property type } \\
& Fiber & & \\
& & & \\
Matrix & Ply \\
Modulus, mpsi $(1,1)$ & 31.0 & 0.5 & 18.8 \\
$(2,2)$ or $(3,3)$ & 2.0 & 0.5 & $1.0 / 1.2^{\mathrm{a}}$ \\
& & & \\
Poisson's ratio, & & & \\
$(1,2)$ or $(1,3)$ & 0.20 & 0.35 & 0.26 \\
$(2,3)$ & 0.25 & 0.35 & 0.42
\end{tabular}

The corresponding ply microstresses (rounded to one decimal place) are:

\begin{tabular}{|c|c|c|}
\hline $\begin{array}{l}\text { Subregion } \\
\text { microstress }\end{array}$ & $\begin{array}{r}\text { Ply microstresses } \\
\sigma_{\ell 22}=7 \mathrm{ks} 1\end{array}$ & $\begin{array}{c}\text { (ksi) for ply stress } \\
\sigma_{\ell 22}=-35 k s i\end{array}$ \\
\hline$\sigma_{m 11}^{(A \text { or } B)}$ & 2.4 & -12.0 \\
\hline$\sigma_{f 11}$ & -1.6 & 8.0 \\
\hline$\sigma_{\mathrm{m} 22}^{(A)}$ & 3.5 & -17.5 \\
\hline$\sigma_{\mathrm{m} 22}^{(\mathrm{B})}$ & 8.4 & -42.0 \\
\hline$\sigma_{f 22}^{(B)}$ & 8.4 & -42.0 \\
\hline$\sigma_{\mathrm{m} 33}^{(\mathrm{A})}$ & -0.2 & 1.5 \\
\hline$\sigma_{\mathrm{m} 33}^{(\mathrm{B})}$ & 0.1 & -0.3 \\
\hline $\begin{array}{l}\text { (B) } \\
\sigma_{f 33}\end{array}$ & 0.1 & -0.3 \\
\hline$\sigma_{122}^{(B)}$ & 8.4 & 42.0 \\
\hline$\sigma_{133}^{(B)}$ & 0.1 & -0.3 \\
\hline$\sigma_{i N}$ & 8.3 & -41.6 \\
\hline$\sigma_{\text {is }}$ & 6.0 & -30.1 \\
\hline
\end{tabular}

$a_{\left(E_{22} / E_{\ell 22}\right)}$ as predicted from the respective equations in figure 8. 
In examining the magnitudes of the above ply microstresses, the following are observed: (1) the ply transverse stress is resisted mostly by the constituents in subregion (B); (2) the longitudinal stress in the matrix has the same sign as the ply transverse stress; (3) the longitudinal stress in the fiber has the opposite sign of the ply transverse stress and is of relatively negligible magnitude compared to corresponding strength; (4) the through-thethickness microstresses in subregions (A) and (B) are negligible in both constituents; (5) the normal interfacial bond stress is of relatively high magnitude in subregion (B); and (6) both interfacial stresses are of relatively high magnitude in subregion (C). It may be concluded, therefore, that the transverse ply stress will generally induce microcracks associated with (in the order of most probable occurrence): (1) interfacial bond and (2) intermatrix matrix fracture.

\section{PLY microstresses dUE TO PLY fLAT-WISE STRESS ( $\sigma_{\ell 33} 3$ )}

The ply flat-wise stress induces microstresses which are similar to those induced by the ply transverse stress but rotated $90^{\circ}$. The similarity is a consequence of the square array unit cell assumption which has the same interfiber and intermatrix structure, the same constituent properties along the 2 and 3 material axes direction, and the same ply properties along the 2 and 3 material axes directions.

The equations to predict stresses in the constituents due to a ply "flat-wise" stress are the same as in figure 8 , but with the subscripts 22 and 33 interchanged. In order to calculate the ply microstresses, first interchange the subscripts in the equations in figure 8 and second follow the procedure described in Example 4.1. The observations and conclusions for this example, relative to microstress magnitudes and probable microfractures, are applicable for the ply flat-wise stress as well but, again, rotated $90^{\circ}$.

\section{PLY MICROSTRESSES DUE TO PLY INTRAPLY SHEAR STRESS $\left(\sigma_{\ell} 12\right.$ or $\left.\sigma_{\ell} 13\right)$}

The equations to predict stresses in the constituents due to an intraply (intralaminar) shear stress are summarized in figure 9 . The schematics in the figure depict the notation used in the equations and their respective subregions. The microstresses depend on relative constituent/ply shear moduli. The dependence of the microstresses on the fiber volume ratio is through the ply shear moduli $G_{12}$ and $G_{\ell 12}$ as shown in the figure. The equations for the shear microstresses in the 13 plane due to ply intraply shear stress $\sigma_{\ell} 13$ are the same as those in figure 9 with the subscripts 12 replaced by 13 .

In order to use the ply microstress equations in figure 9 , we need one fiber property $\left(G_{f 12}\right)$, one matrix property $\left(G_{m}\right)$, two different ply sheer moduli ( $G_{12}$ and $\left.G_{l 12}\right)$, the fiber volume ratio $\left(k_{f}\right)$, and the intrapiy shear stress $\left(\sigma_{\ell} 12\right)$. The fiber and matrix properties are obtained from tables 1 and 2. The two ply sheer modulf are calculated from the equations shown in the figure. The ply fiber volume ratio and the intraply shear stress are assumed known. The following example fllustrates use of the equations.

Example 6.1.: Determine the constituent stresses (ply microstresses) in an AS/IMHS ply with 0.6 fiber volume ratio and $10 \mathrm{ksi}$ intraply shear stress. 
An intraply stress of $10 \mathrm{ksi}$ is about equal to the intralaminar fracture stress.

Solution: The required computations are expedited by proceeding as follows: (1) select respective constituent material properties from tables 1 and 2; (2) calculate ply shear moduli from the respective equations in figure 9; (3) substitute these properties in the microstress equations together with the intraply shear stress; (4) calculate the microstresses from the appropriate equations in figures 9 and 6 (for the interfacial bond); and (5) summarize the results. For this example, the constituent material and piy properties are:

$\begin{array}{cccc}\text { Property, units } & \text { Fiber } & \begin{array}{c}\text { Property type } \\ \text { Matrix }\end{array} & \text { Ply } \\ \text { Shear modulus, mpsi } & 2.0 & 0.19 & 0.54 / 0.64^{\mathrm{a}}\end{array}$

The corresponding ply microstresses (rounded to one decimal place) are:

$\begin{array}{cc}\begin{array}{c}\text { Subregion } \\ \text { microstress }\end{array} & \begin{array}{c}\text { Ply microstresses (ksi) } \\ \text { for intraply shear stress } \\ \sigma_{\ell 12}=10 \mathrm{ksi}\end{array} \\ \sigma_{\mathrm{m} 12}^{(A)} & 3.5 \\ (B) & 11.9 \\ \sigma_{\mathrm{m} 12} & 11.9 \\ (B) & 11.9 \\ \sigma_{\mathrm{f} 12} & \\ (B) & 0 \\ \sigma_{112} & \\ \text { Al1 others } & \end{array}$

Examining the magnitudes of the above microstresses the following are observed: (1) the shear microstress in the matrix in the interfiber region (B) is substantial and about 90 percent of the matrix shear strength ( $13 \mathrm{ksi}$, table 2); (2) the interfacial shear stress exceeds the ply intralaminar shear strength (about $10 \mathrm{ksi}$ ); (3) the shear microstress in the matrix in subregion (A) is relatively low compared to both intralaminar shear strength and matrix shear strength. It may be concluded, therefore, that the intraply shear stress will generally induce microcracks associated with (in the order of most probable occurrence) (1) interfacial bond or interfiber matrix fracture and (2) intermatrix matrix fracture. Interfiber matrix fracture is equally probable since the magnitude of the shear microstress is so close to the shear strength of the matrix. It is the equally probable occurrence of either interfacial bond fracture or interfiber matrix fracture that explains, in part, the sensitivity of intralaminar or interlaminar shear strength to: (1) interfacial bonding conditions, (2) environmental effects on matrix dominated composite properties, and (3) matrix effects on composite properties, in general.

$a_{G_{12}} / G_{\ell 12}$. 
As was already mentioned, ply interlaminar shear stress $\left(\sigma_{\ell 13}\right.$ ) will induce the same microstress magnitudes in the 1-3 plane. The calculation procedure, observations, and conclusions are also the same.

\section{PLY MICROSTRESSES DUE TO PLY THROUGH-THE-THICKNESS SHEAR STRESS $\left(\sigma_{\ell 23}\right)$}

The equations to predict the stresses in the constituents due to a throughthe-thickness shear stress are summarized in figure 10. The schematics in the figure depict the notation used in the equations and their respective subregions. The microstresses depend on relative constituent/ply shear moduli. The dependence of the microstress on the fiber volume ratio is through the ply shear moduli $G_{23}$ and $G_{\ell 23}$ as shown in the figure.

In order to use the ply microstress equations in figure 10 , we need to know one fiber property $\left(G_{f 23}\right)$, one matrix property $\left(G_{M}\right)$, two ply properties $\left(G_{23}\right.$ and $\left.G_{223}\right)$, the fiber volume ratio $\left(k_{f}\right)$, and the throughthe-thickness ply shear stress $\left(\sigma_{\ell 23}\right)$. The fiber and matrix properties are obtained from tables 1 and 2. The ply properties are calculated from the equations shown in the figure. The ply fiber volume ratio and the ply through-the-thickness shear stress are assumed known. The following example illustrates use of the equations.

Example 7.1.: Determine the stresses in the constituents (piy microstresses) in an AS/IMHS ply with 0.6 fiber volume ratio assuming a $6 \mathrm{ksi}$ through-the-thickness ply shear stress. This shear stress is approximately equal to the corresponding ply shear strength which is estimated to be about 60 percent of the intralaminar shear strength (10 ksi previous section).

Solution: The required computations are expedited by proceeding as follows: (1) select respective constituent material properties from tables 1 and $2 ;(2)$ calculate the ply shear moduli from the respective equations in figure 10; (3) substitute these properties in the microstress equations together with the ply through-the-thickness shear stress; (4) calculate the microstresses from the appropriate equations in figures 10 and 6 (for interfacial bond); and (5) summarize the results. For this example, the constituent material and ply properties are:

Property, units

Shear modulus, mpsi

\section{Fiber}

Property type

Matrix Ply

$1.0 \quad 0.19$

$0.51 / 0.37^{a}$

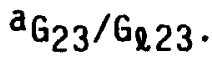


The corresponding ply microstresses (rounded to one decimal place) are:

\begin{tabular}{|c|c|}
\hline $\begin{array}{l}\text { Subregion } \\
\text { microstress }\end{array}$ & $\begin{array}{l}\text { Ply microstresses } \\
\text { (ksi) for through- } \\
\text { the-thickness ply } \\
\text { shear stress } \\
\sigma_{\ell 23}=6 \mathrm{ksi}\end{array}$ \\
\hline $\begin{array}{l}(A) \\
\sigma_{m 23}^{(A)} \\
\sigma_{m 23}^{(B)} \\
(B) \\
\sigma_{f 23} \\
(B) \\
\sigma_{123}^{(B)} \\
(C) \\
\sigma_{i N}\end{array}$ & $\begin{array}{l}8.3 \\
8.3 \\
8.3 \\
6.0\end{array}$ \\
\hline All others & 0 \\
\hline
\end{tabular}

Examining the magnitudes of the above microstresses the following are observed: (1) the shear microstresses in the matrix in the interfiber subregion $B$ are substantial compared to the corresponding ply shear strength ( 6 ks1): (2) the interfacial bond shear strength in the interfiber subregion $B$ is also substantial; (3) the interfacial bond normal stress in subregion (C) is equal to the through-the-thickness shear strength; and (4) the matrix microstress in the intermatrix subregion (A) is about 50 percent of the corresponding ply shear strength. It may be concluded, therefore, that the through-the-thickness ply shear stress will generaliy induce microcracks assoclated with (in the order of most probable occurrence) (1) interfacial bond or interfiber matrix fracture and (2) intermatrix matrix fracture. If it is assumed that the interfaclal bond is the weakest link, then the microcracks will develop at this location first. Subsequently the microcracks will progress to the intermatrix subregion and produce transply crack or ply fracture.

It is interesting to note that the interfacial bond microstress magnitudes for this example are almost identical to those for the ply transverse tensile stress in Example 4.1. One conjecture may be that both of these ply stresses induce ply fracture which initiates at the interface and, therefore, the corresponding ply strengths are interfacial bond-strength controlled. This is consistent with the general consensus view in the composites community.

\section{PLY MiCROSTRESSES DUE TO TEMPERATURE CHANGE $\left(\Delta \mathrm{T}_{\ell}\right)$}

The equations to predict the stresses in the constituents due to a temperature change in the ply are summarized in figure 11. The schematics in the figure depict the notation used in the equations and their respective subregions. The ply microstresses due to temperature change depend on the relative constituent materials/ply thermal expansion coefficients, the constituent 
materials moduli, and on the fiber volume ratio. These microstresses also depend on the fiber volume ratio and the ply longitudinal modulus through the ply thermal expansion coefficients as shown in the figure.

In order to use the ply microstress equations in figure 11 , we need to know three fiber properties $\left(\alpha_{f 11}, \alpha_{f 22}\right.$, and $\left.E_{f 11}\right)$, three matrix properties ( $\alpha_{m}, E_{m}$ and $\left.v_{m}\right)$, three ply properties $\left(\alpha_{\ell} 11, \alpha_{\ell 22}\right.$, and $\left.E_{\ell 11}\right)$, the fiber volume ratio $\left(k_{f}\right)$, and the temperature change in the ply $\left(\Delta T_{\ell}\right)$. The fiber and matrix properties are obtained from tables 1 and 2. The ply properties are calculated from the equations shown in the figure. The ply fiber volume ratio and the ply temperature change are assumed known. The following example lllustrates use of the equations.

Example 8.1: Determine the stresses in the constituents (ply microstresses) in an AS/IMHS ply with 0.6 fiber volume ratio and only subjected to $300^{\circ} \mathrm{F}$ ply temperature change. This temperature change corresponds to the temperature difference between cure temperature and room temperature. It was selected to determine the magnitude of the residual microstresses.

Solution: The required computations are expedited by proceeding as follows: (1) select respective constituent material properties from tables 1 and 2 ; (2) calculate the ply longitudinal modulus and the ply thermal expansion coefficients from the respective equations in figure 11 ; (3) substitute appropriate properties in the microstress equations together with fiber volume ratio and the temperature change; (4) calculate the microstresses from the appro-

priate equations in figures 11 and 6 (for interfacial bond); and (5) summarize the results. For this example the constituent material and ply properties are:

\begin{tabular}{clcc} 
Property, unit & \multicolumn{3}{c}{ Property type } \\
& Fiber Matrix & Ply \\
Modulus, mpsi $(1,1)$ & 31 & 0.5 & 18.8 \\
Poisson's ratio $(1,2)$ & 0.20 & 0.35 & 0.26 \\
Thermal expansion & & & \\
coefftcients, & & & \\
Hin/in/ $\mathrm{F}$ & & & \\
$(1,1)$ & -0.55 & 36 & -0.16 \\
$(2,2)$ & 5.6 & 36 & 15.3
\end{tabular}

The corresponding ply microstresses (rounded to one decimal place) are:

$\begin{array}{cc}\begin{array}{c}\text { Subregion } \\ \text { microstress }\end{array} & \begin{array}{l}\text { Ply microstresses } \\ (k s i) \text { for a ply } \\ \text { temperature change } \\ \Delta T_{\ell}=-300^{\circ} \mathrm{F}\end{array} \\ \sigma_{\mathrm{m} 11} & 5.4 \\ \sigma_{\mathrm{f} 11} & -3.6 \\ (\mathrm{~A}) & 3.1 \\ \sigma_{\mathrm{m} 22} & -0.9 \\ \sigma_{\mathrm{m} 22} & \end{array}$




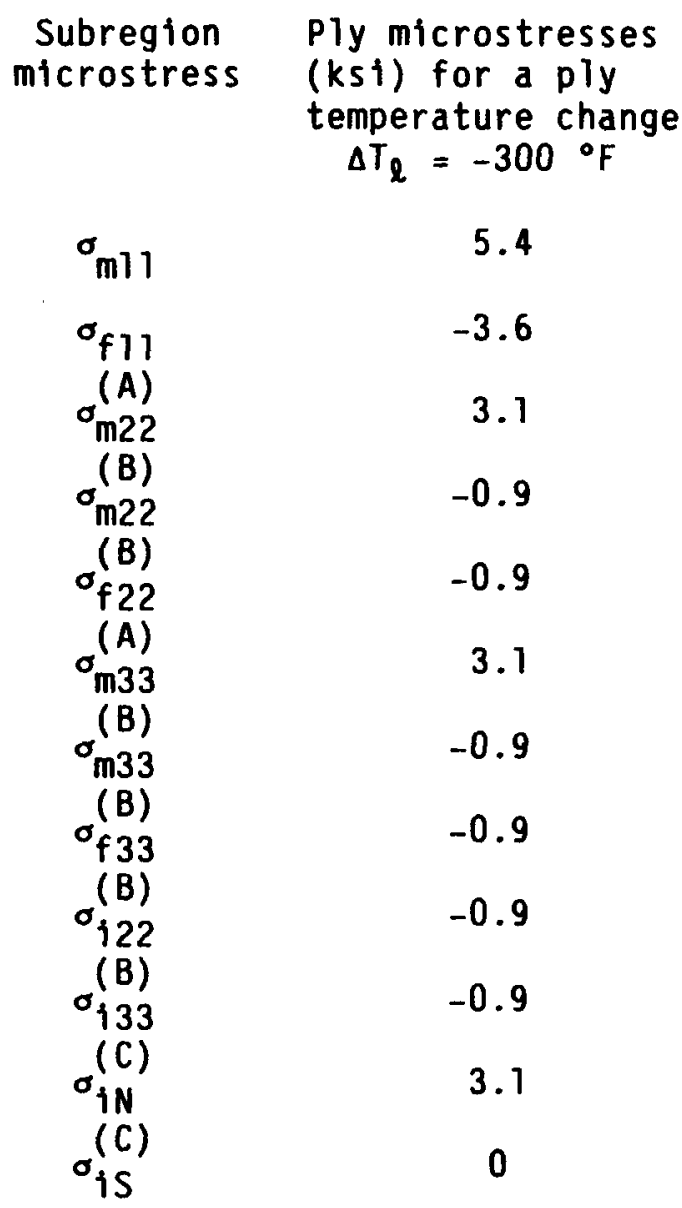

Examining the magnitudes of the residual microstresses due to cure temperature $\left(\Delta \mathrm{T}_{\ell}=-300^{\circ} \mathrm{F}\right)$ the following are observed: (1) the longitudinal microstresses are relatively low compared to corresponding constituent material strengths; (2) the microstresses in the matrix in both subregions (A) and (B) are also low; and (3) the normal microstress in the interfacial bond (subregion (C) may be substantial compared to a typical tensile bond strength of about $1 \mathrm{ksi}$. It may be concluded, therefore, that the residual microstress could induce microcracks at the interface in subregion (C). These microcracks can subsequently extend into the intermatrix subregion (A).

\section{PLY MICROSTRESSES DUE TO MOISTURE CHANGE $\left(M_{\ell}\right)$}

The equations to predict the stresses in the constituents due to a moisture change in the ply are summarized in figure 12. The schematics in the figure depict the notation used in the equations and their respective subregions. The microstresses due to moisture change depend on the relative constituent materials ply/moisture expansion coefficients, the corresponding moduli, and on the fiber volume ratio. These microstresses also depend on the fiber volume ratio and the ply moduli through the ply moisture expansion coefficients as shown in the figure.

In order to use the ply microstress equations in figure 12 , we need to know two fiber properties $\left(E_{f 11}\right.$ and $\left.E_{f 22}\right)$, two matrix properties $\left(B_{m}\right.$ and $E_{m}$ ), four ply properties ( $\beta_{\ell 11}, B_{\ell 22}, E_{\ell 11}$ and $E_{\ell 22}$ ), the fiber volume ratio $\left(k_{f}\right)$, and the molsture change in the ply $\left(M_{l}\right)$. The fiber and 
matrix properties are obtained from tables 1 and 2 . The ply properties are calculated from the equations shown in the figure. The ply fiber volume ratio and the ply molsture change are assumed known. The following example illustrates use of the equations.

Example 9.1: Determine the stresses in the constituents (ply microstresses stresses) in an AS/IMHS ply with 0.6 fiber volume ratio assuming only 1.8 wt \% ply moisture content. This moisture change corresponds approximately to composite moisture saturation under normal exposure conditions. It was selected to determine the magnitude of the ply microstresses due to these normal moisture exposure conditions.

Solution: The required computations are expedited by proceeding as fol. lows: (1) select respective constituent material properties from tables 1 and 2 ; (2) calculate the ply moduli and the ply moisture expansion coefficients from the respective equations in figure 12 ; (3) substitute appropriate properties in the microstress equations together with fiber volume ratio and the moisture change; (4) calculate the microstresses from the appropriate equations in figure 12 and for interfacial bond in figure 6; and (5) summarize the results. For this example the constituent material and ply properties are:

\begin{tabular}{lrrr} 
Property, units & \multicolumn{3}{c}{$\begin{array}{c}\text { Property type } \\
\text { Fiber }\end{array}$} \\
Matrix & Ply \\
Modulus, mpsi $(1,1)$ & 31 & 0.5 & 18.6 \\
$(2,2)$ & 2.0 & 0.5 & 1.2 \\
& & & \\
Moisture expansion & & & \\
coefficients, & & & \\
in/in/\% M & & & \\
$(1.1)$ & 0 & 0.33 & 0.0035 \\
$(2,2)$ & 0 & 0.33 & 0.0806
\end{tabular}

The corresponding ply microstresses (rounded to one decimal place) are:

$\begin{array}{cc}\begin{array}{c}\text { Subregion } \\ \text { microstress }\end{array} & \begin{array}{c}\text { Ply microstresses } \\ \text { (ksi) for a ply } \\ \text { moisture change } \\ M_{\ell}=1.8 \text { percent }\end{array} \\ \sigma_{m 11} & -0.3 \\ \sigma_{f 11} & 0.2 \\ \sigma_{m 22}^{(A)} & -0.2 \\ \sigma_{m 22}^{(B)} & 0.1 \\ \sigma_{f 22}^{(B)} & 0.1 \\ \sigma_{m 33}^{(A)} & 0.2 \\ \sigma_{m 33}^{(B)} & 0.1\end{array}$




$\begin{array}{cl}\text { Subregion } & \text { Ply microstresses } \\ \text { microstress } & \text { (ksi) for a ply } \\ & \text { moisture change } \\ & M_{Q}=1.8 \text { percent }\end{array}$

$\begin{array}{cc}\sigma_{f 33}^{(B)} & 0.1 \\ \sigma_{i 22}^{(B)} & 0.1 \\ \sigma_{i 33}^{(B)} & 0.1 \\ \sigma_{i N}^{(C)} & 0.1 \\ \sigma_{i S}^{(C)} & 0\end{array}$

Examining the magnitudes of the moisture (hygral) microstresses due to a moisture change of 1.8 wt $\%$, the following are observed: (1) the longitudinal microstresses are relatively negligible compared to corresponding constituent material strengths; (2) the microstresses in the matrix in both subregions (A) and (B) are also negligible; and (3) the normal microstress in the interface bond (subregion (C)) is negligible compared to a typical tensile bond strength of about $1 \mathrm{ksi}$. It may be concluded, therefore, that the hygral microstress would not induce microcracks at the interface in either subregion (B) or (C).

\section{DISCUSSION}

The several numerical examples presented and discussed fllustrate the usefulness and advantage of having a unified set of micromechanics equations summarized in figures 6 to 12 for predicting ply microstresses. The examples also lllustrate how the various microstresses are interrelated and dependent on constituent and ply properties. In addition they provide detailed and quantitative information of the ply microstresses in the various subregions and also possible sites of microcrack formations. Furthermore, the various microstress equations can be selectively used to conduct parametric studies as well as sensitivity analyses to assess the influence of constituent materials, fiber volume ratio, and mechanical and environmental load conditions on ply microstresses and possible microcrack formations.

The two tables summarizing constituent material properties illustrate the amount of data needed for effective use of a unified set of micromechanics equations. The data in these tables were complled from many sources and many values are estimates which were inferred from predicted results and curve fits. The data are included for three main reasons: (1) to 11lustrate that the use of these micromechanics equations require numerous property data; (2) to bring attention to the fact that many of these properties have not been measured and, hopefully, stimulate enough interest to develop experimental methods to measure them; and (3) to provide indicative ranges of properties of both fibers and matrices. It cannot be overemphasized that the data should be considered dynamic in the sense that they should be continuously modified if better values are known or become available. 
Lastly, the unified set of micromechanics equations described herein for microstresses can be used to determine the effects of voids, moisture, and temperature on the magnitudes of the microstresses. This is accomplished by first predicting the effects of these variables on matrix and ply properties using the procedures described in references 1 and 2 . These modified properties are then used in the ply microstress equations to predict the resulting effect. The equations can also represent microstress/ply stress influence coefficients simply by dividing the desired microstress with its respective ply stress.

\section{CONCLUSIONS}

A unified set of micromechanics equations of simple form is summarized and described for predicting ply microstresses. The unified set of equations consists of simplified expressions to predict microstresses in the matrix, give the interface, and in the fiber for hygral, thermal, and mechanical loading conditions. Several examples are presented to illustrate usefulness of these equations and attendant significance to the structural integrity and damage tolerance of fiber composites. The availability of this unified set of equations makes it possible to explain the origin of microcracking and provide a basis for determining the damage initiation at the fiber composite microscale. 


$\begin{array}{ll}E & \text { modulus of elasticity } \\ G & \text { shear modulus } \\ K & \text { volume ratio } \\ M & \text { moisture, wt } x \\ T & \text { temperature } \\ X, y, z & \text { structural reference axes } \\ T, 2,3 & \text { ply material axes } \\ \alpha & \text { thermal expansion coefficient } \\ B & \text { moisture expansion coefficient } \\ E, E & \text { fracture strain, strain } \\ v & \text { Poisson's ratio } \\ \sigma & \text { stress }\end{array}$

Subscripts:

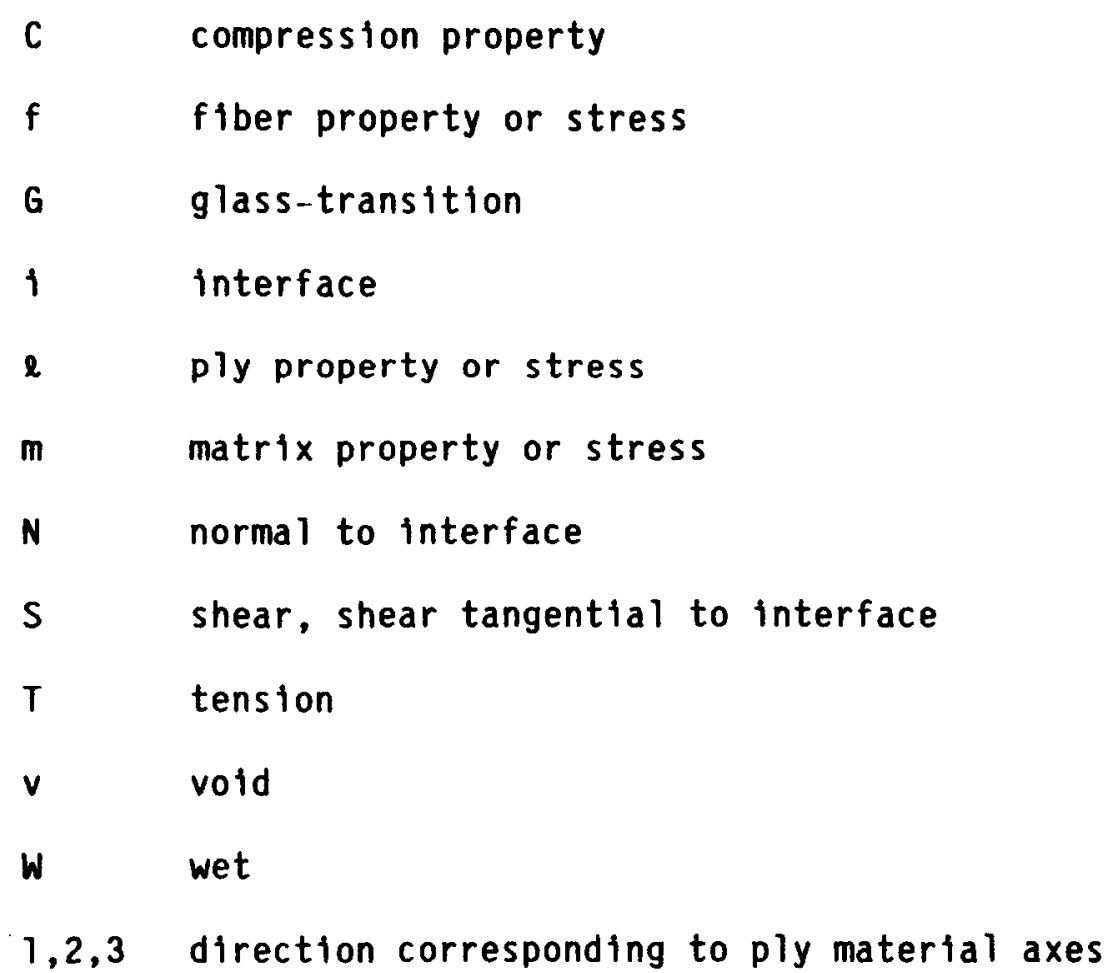




\section{Superscripts:}

A microstress in intermatrix subregion (A)

B microstress in interfiber subregion (B)

C microstress in the interface in intermatrix region (C) 


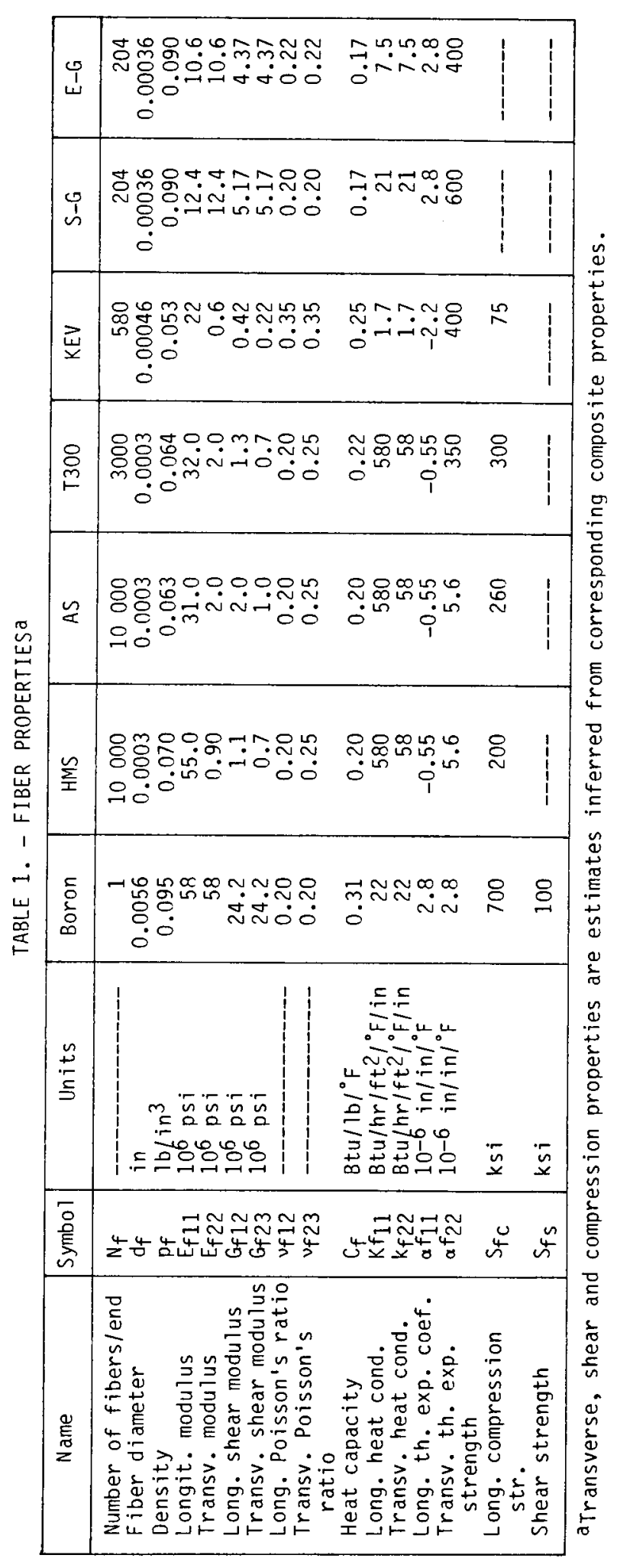


TABLE 2. - MATRIX PROPERTIES

\begin{tabular}{|c|c|c|c|c|c|c|c|c|}
\hline \multicolumn{3}{|c|}{ Property } & \multicolumn{6}{|c|}{ Matrix } \\
\hline Name & Symbol & Units & LM & IMLS & IMHS & HM & $\begin{array}{l}\text { Poly- } \\
\text { imide }\end{array}$ & PMR \\
\hline $\begin{array}{l}\text { Density } \\
\text { Modulus }\end{array}$ & ${ }^{\rho_{m}}$ & $1 \mathrm{~b} /$ in 13 & $\begin{array}{r}0.042 \\
0.32\end{array}$ & $\begin{array}{r}0.046 \\
0.50\end{array}$ & $\begin{array}{r}0.044 \\
0.50\end{array}$ & $\begin{array}{r}0.045 \\
0.75\end{array}$ & $\begin{array}{r}0.044 \\
0.50\end{array}$ & $\begin{array}{r}0.044 \\
0.47\end{array}$ \\
\hline Shear modulus & $G_{m}^{\prime \prime}$ & $10^{6} \mathrm{psi}$ & $---\infty$ & & & & & \\
\hline $\begin{array}{l}\text { Poisson's ratio } \\
\text { Heat capacity }\end{array}$ & $v_{m}$ & $\mathrm{Btu} / \mathrm{lb} /{ }^{\circ} \mathrm{F}$ & $\begin{array}{l}0.43 \\
0.25\end{array}$ & $\begin{array}{l}0.41 \\
0.25\end{array}$ & $\begin{array}{l}0.35 \\
0.25\end{array}$ & $\begin{array}{l}0.35 \\
0.25\end{array}$ & $\begin{array}{l}0.35 \\
0.25\end{array}$ & $\begin{array}{l}0.36 \\
0.25\end{array}$ \\
\hline Heat conductivity & $k_{m}^{m}$ & Btu/hr/ft $\mathrm{ft}^{2} /{ }^{\circ} \mathrm{F} /$ in & 1.25 & 1.25 & 1.25 & 1.25 & 1.25 & 1.25 \\
\hline Thermal exp. coef. & $\alpha_{m}$ & $10^{-6} \mathrm{in} / \mathrm{in} /{ }^{\circ} \mathrm{F}$ & 57 & 57 & 36 & 40 & 20 & 28 \\
\hline Diffusivity & $D_{m}$ & $10^{-10} \mathrm{in}^{2} / \mathrm{sec}$ & $\begin{array}{l}0.6 \\
0.32\end{array}$ & 0.6 & 0.6 & 0.6 & 0.6 & 0.6 \\
\hline $\begin{array}{l}\text { Moisture exp. coef. } \\
\text { Tensile strength }\end{array}$ & ${ }_{S_{m t}^{B} m}^{m}$ & $\begin{array}{l}\mathrm{in} / \mathrm{in} / \% \mathrm{M} \\
\mathrm{ksi}\end{array}$ & $\begin{array}{r}0.33 \\
8\end{array}$ & $\begin{array}{r}0.33 \\
7\end{array}$ & $\begin{array}{r}0.33 \\
15\end{array}$ & $\begin{array}{r}0.33 \\
20\end{array}$ & $\begin{array}{r}0.33 \\
15\end{array}$ & $\begin{array}{r}0.33 \\
8\end{array}$ \\
\hline Compression strength & $S_{m c}$ & ksi & 15 & 21 & 35 & 50 & 30 & 16 \\
\hline Shear strength & $\mathrm{S}_{\mathrm{ms}}^{\mathrm{m}}$ & $k s i$ & 8 & 70 & 13 & 15 & 13 & 8 \\
\hline $\begin{array}{l}\text { Tensile fracture } \\
\text { strain }\end{array}$ & Ent & in/in $(\%)$ & 8.1 & 1.4 & 2.0 & 2.0 & 2.0 & 2.0 \\
\hline $\begin{array}{l}\text { Compr. fracture } \\
\text { strain }\end{array}$ & $\varepsilon_{\mathrm{mc}}$ & $\mathrm{in} / \mathrm{in}(\%)$ & 15 & 4.2 & 5.0 & 5.0 & 4.0 & 3.5 \\
\hline $\begin{array}{l}\text { Shear fracture } \\
\text { strain }\end{array}$ & Ems & in/in (\%) & 10 & 3.20 & 3.5 & 4.0 & 3.5 & 5.0 \\
\hline $\begin{array}{c}\text { Air heat conductivity } \\
\text { Glass trans. temp. } \\
\text { (dry) }\end{array}$ & $\begin{array}{l}K_{V} \\
T_{G D}\end{array}$ & $\underset{F}{B} t u / h r / f t^{2} /{ }^{\circ} F /$ in & $\begin{array}{r}0.225 \\
350\end{array}$ & $\begin{array}{r}0.225 \\
420\end{array}$ & $\begin{array}{r}0.225 \\
420\end{array}$ & $\begin{array}{r}0.225 \\
420\end{array}$ & $\begin{array}{r}0.225 \\
700\end{array}$ & $\begin{array}{r}0.225 \\
700\end{array}$ \\
\hline
\end{tabular}

Notes: LM - Low modulus; IMLS - Intermediate modulus low strength; IMHS = Intermediate modulus high strength; HM - High modulus.

Thermal, hygral, compression and shear properties are estimates only; $G_{m}=E_{m} / 2\left(1+\nu_{m}\right)$. 
CONCEPTS. MATH-MODELS AND EQUATIONS USED TO PREDICT FIBER COMPOSITE PLY MICROSTRESSES, AND MICROCRACKING KNOWING CONSTITUENT MATERIALS/PROPERTIES, GEOMETRIC CONFIGURATION, FABRICATION VARIABLES AND MECHANICAL, HYGRAL AND THERMAL PLY STRESSES

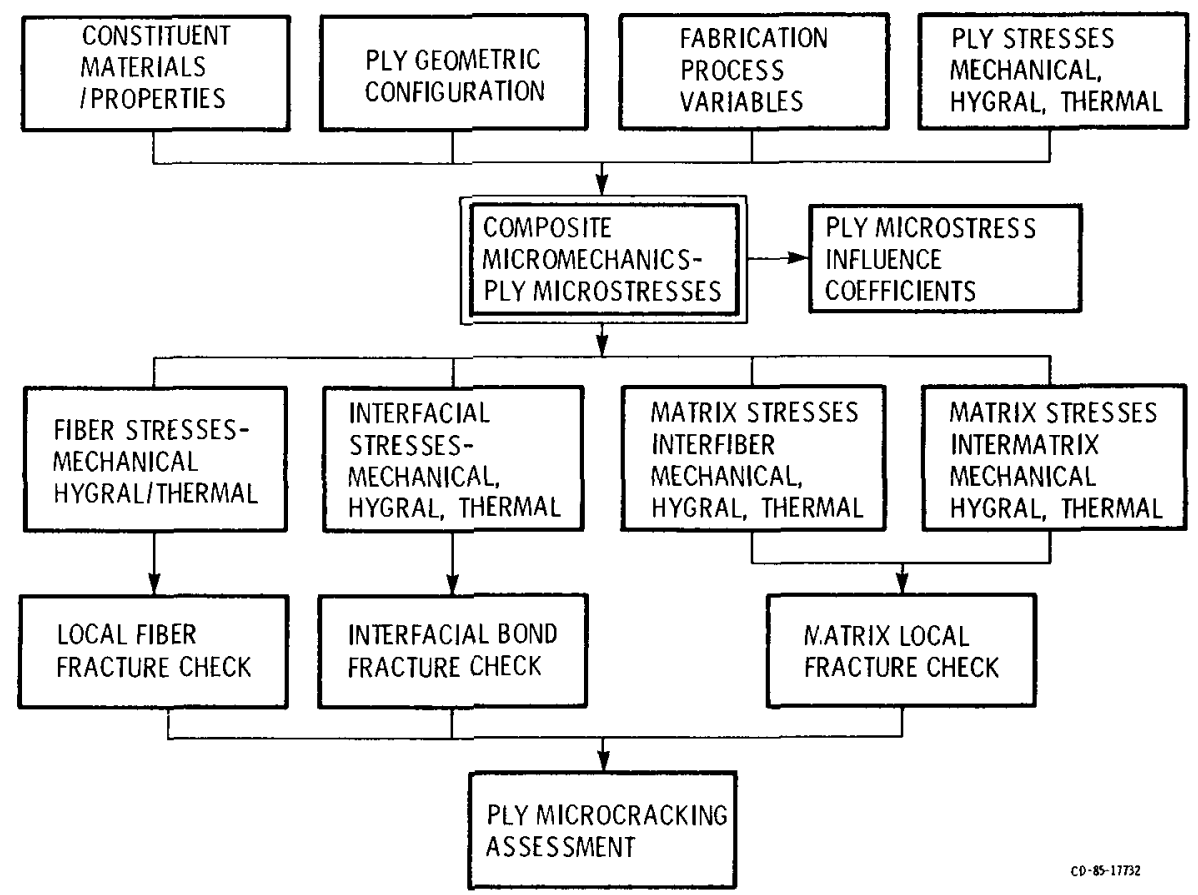

Figure 1. - Simplified composite micromechanics for predicting microstresses-definition.

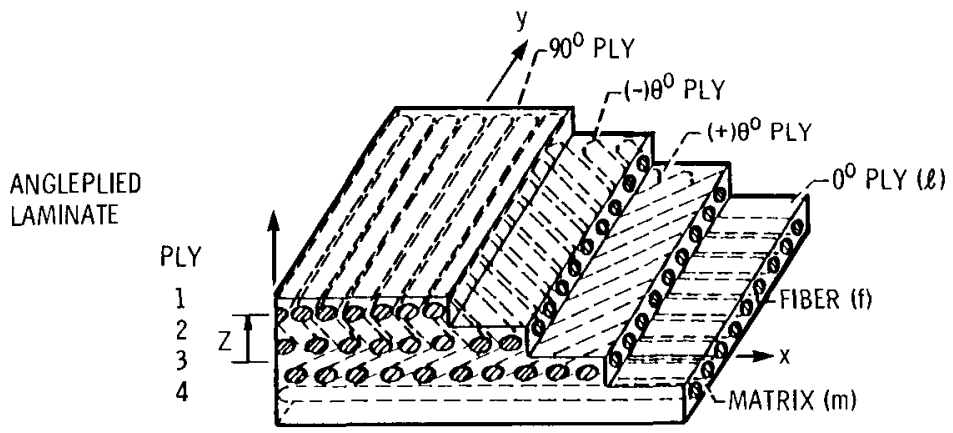

PLY

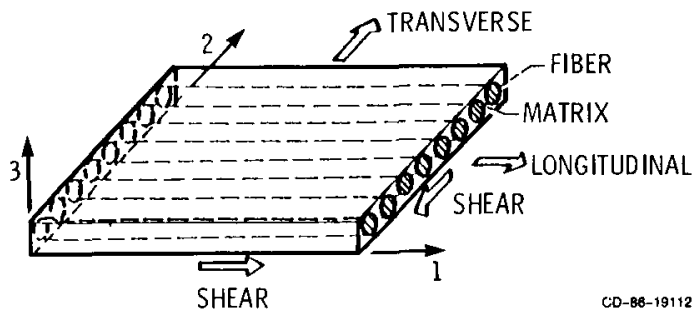

Figure 2. - Typical fiber composite geometry. 


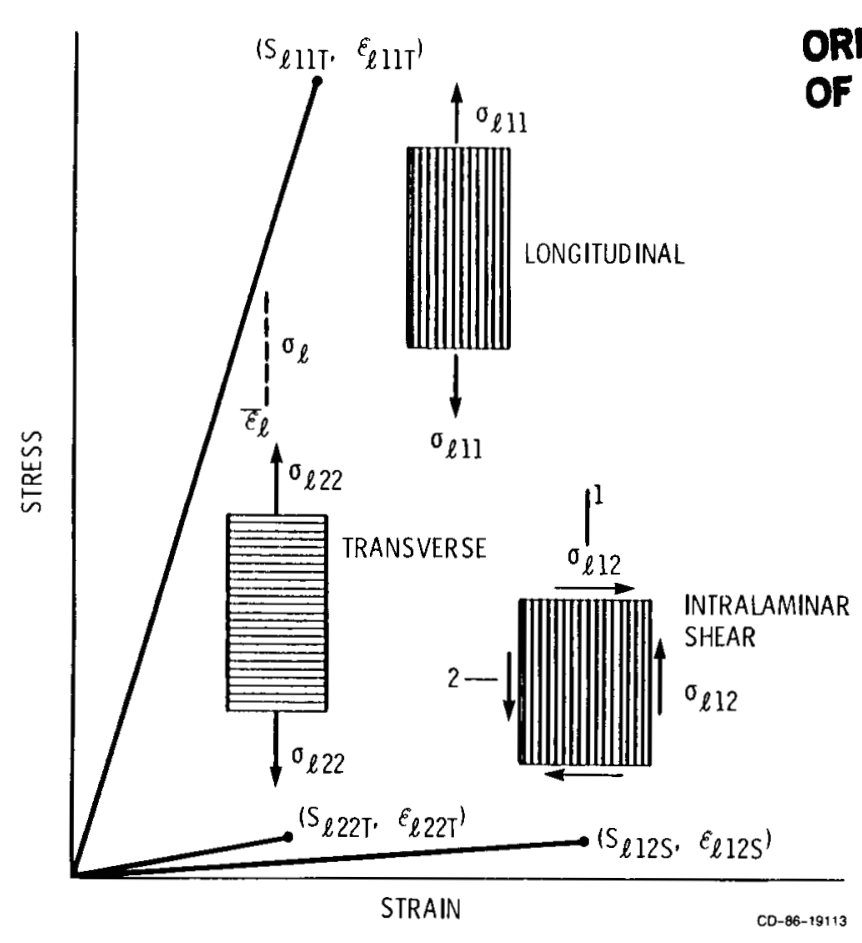

ORIGINAL PAGE IS OF POOR QUALTT

Figure 3. - Typical stress-strain behavior of unidirectional fiber composites.

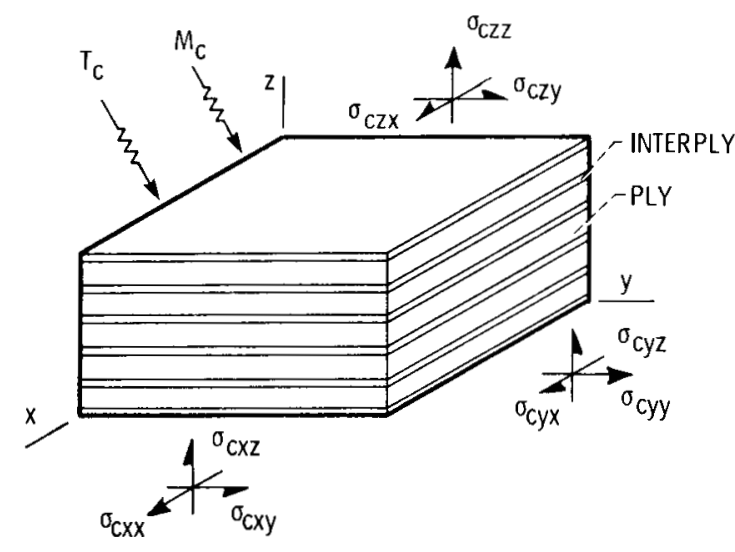

COMPOSITE STRESSES $\left(\sigma_{C}\right)$
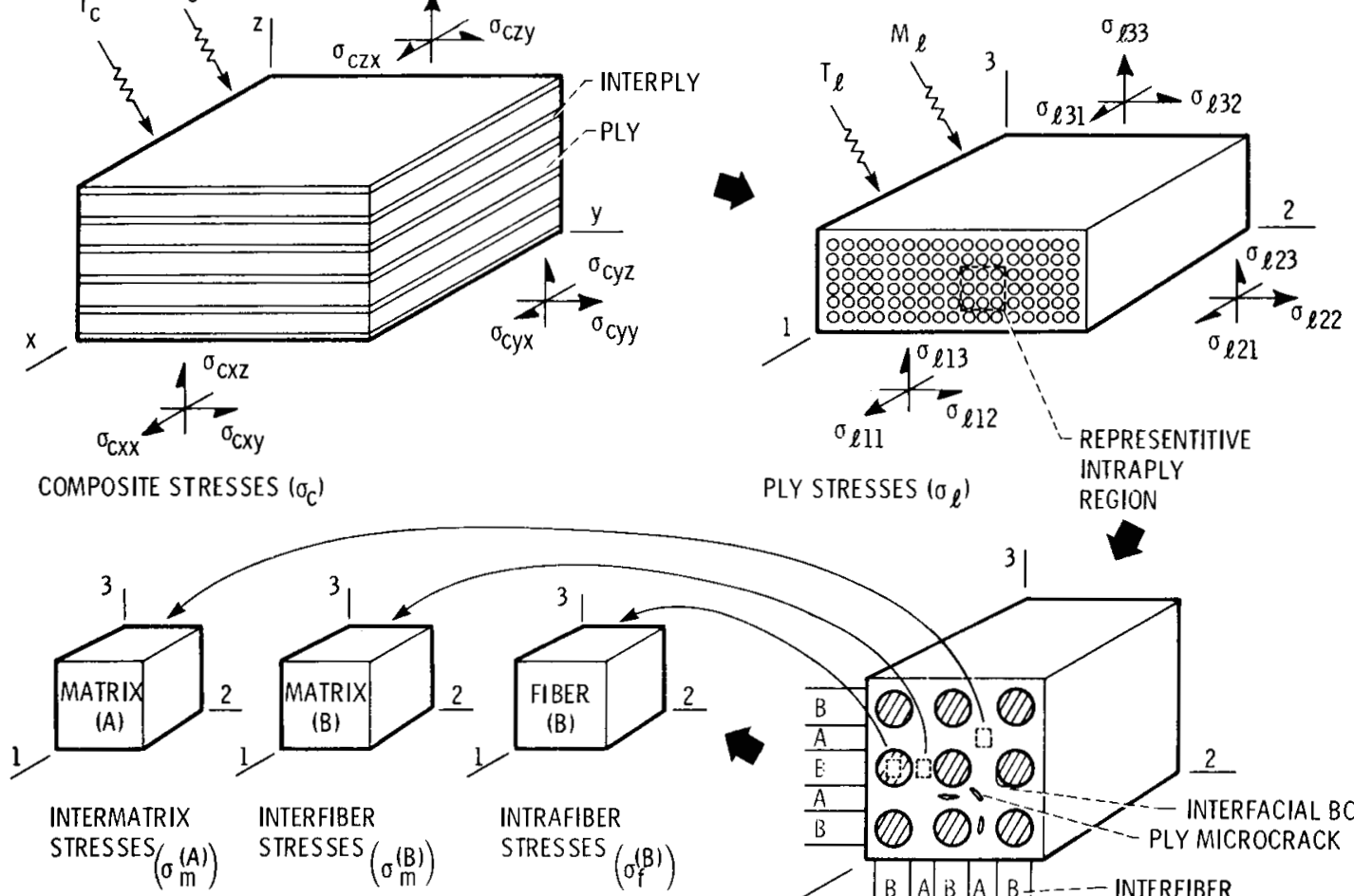

PLY STRESSES $\left(\sigma_{\ell}\right)$

REGION

PLYMICROSTRESSES
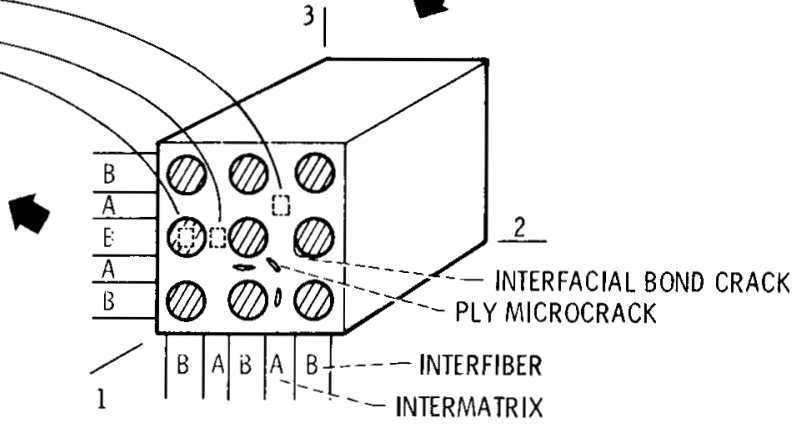

Figure 4. - Ply microstresses through composite stress progressive decomposition. 


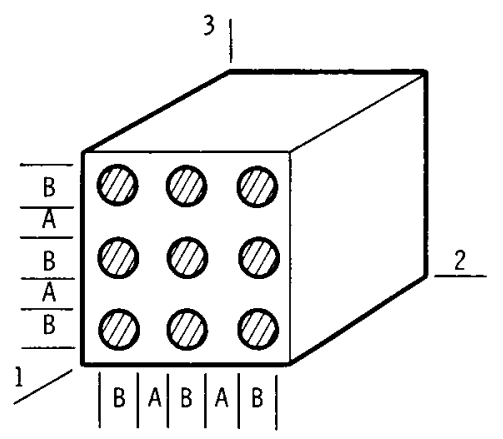

REPRESENTATIVE INTRAPLY REGION

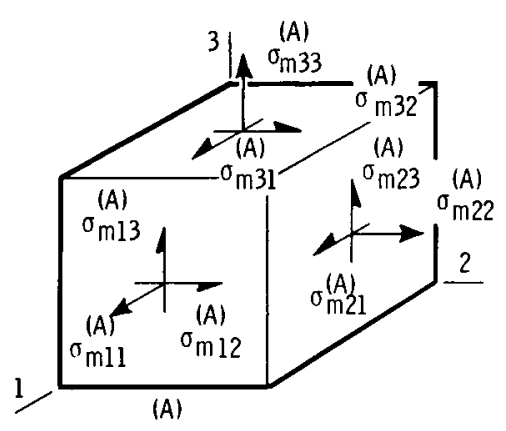

INTERMATRIX

"SUB-REGION" (A) (A)

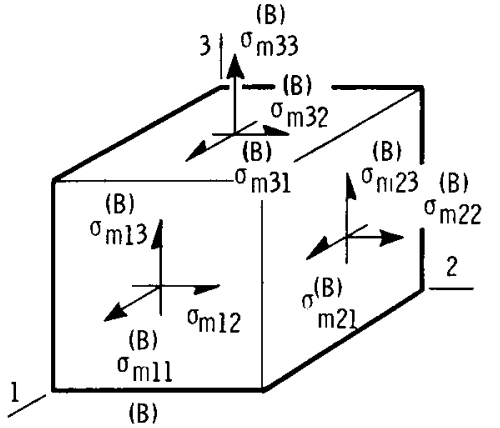

INTERFIBER

"SUB-REGION" (B) ( (B)

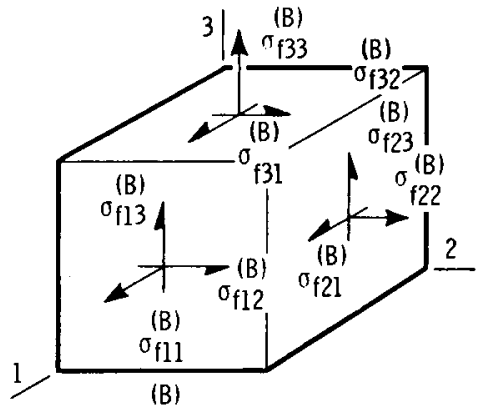

INTRAFIBER

"SUB-REGION" (B) (B) FIBER STRESSES $\left(\sigma_{\mathfrak{f}}\right)$

Figure 5. - Sub-region ply microstresses definition/notation.

INTERMATRIX (A)

$\sigma_{i 22}^{(A)}=\underset{\sigma_{i 33}}{(A)} \approx 0$

INTERFIBER (B)

$\underset{\sigma_{i 22}}{(B)}=\stackrel{(B)}{\sigma_{m 22}}$

$\sigma_{i 33}^{(B)}=\stackrel{(B)}{\sigma_{m 33}}$

$\sigma_{i 12}^{(B)}=\underset{m 12}{(B)}$

INTERMATRIX (C)

$\begin{array}{r}(C) \\ \sigma_{i N}\end{array}=\left\{\left[\left(\begin{array}{cc}(A) & (B) \\ \sigma_{m 22} & +\sigma_{m 22}\end{array}\right)\right.\right.$

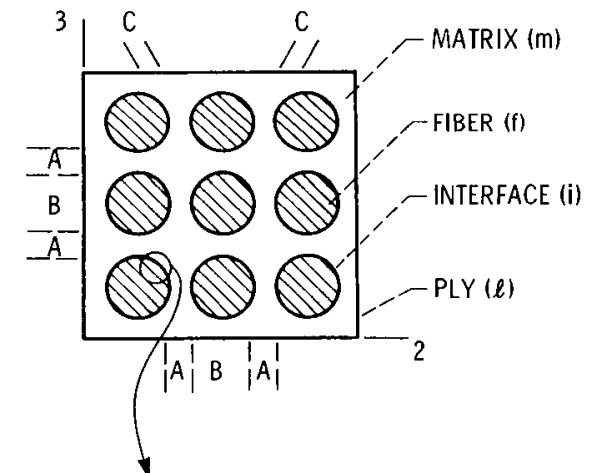

$$
\begin{gathered}
\left.+\left(\sigma_{m 33}^{(A)}+\sigma_{m 33}^{(B)}\right)\right] \times \frac{\sqrt{2}}{2} \\
\left.+\sigma_{\ell 23}\right\} \\
\sigma_{i S}^{(C)}=[(-(A)+(B) \\
\left.\sigma_{m 22}^{(B)}+\sigma_{m 22}^{(}\right) \\
\left.+\left(\sigma_{m 33}^{(A)}+\sigma_{m 33}^{(B)}\right)\right] \times \frac{1}{2}
\end{gathered}
$$

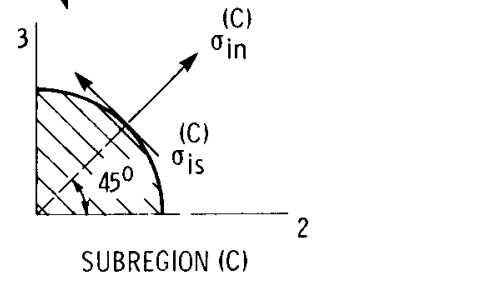

Figure 6. - Ply microstresses - stresses at the interface. 
DUE TO LONGITUDINAL STRESS $\left(\sigma_{\ell 11}\right)$

$\sigma_{m l l}=\left(E_{m} / E_{\ell l 1} / \sigma_{\ell l l}\right.$

$\sigma_{f l l}=\left(E_{f l 1} / E_{\ell 11}\right) \sigma_{\ell l 1}$

$\underset{\sigma_{m 22}}{(A)}=\left(v_{m}-v_{\ell 12}\right)\left(E_{m} / E_{\ell 11}\right) \sigma_{\ell 11}$

$\sigma_{m 22}^{(B)}=-\left(\frac{1-\sqrt{k_{f}}}{\sqrt{k_{f}}}\right) \sigma_{m 22}^{(A)}$

$\underset{f 22}{(B)}=-\left(\frac{1-\sqrt{k_{f}}}{\sqrt{k_{f}}}\right) \quad \begin{array}{r}(A) \\ \sigma_{m 22}\end{array}$

$E_{\ell 11}=k_{f} E_{f 11}+k_{m} E_{m}$

$v_{\ell l 2}=k_{f} v_{f 12}+k_{m} v_{m}$

$\stackrel{(A)}{\sigma_{m 33}}=\stackrel{(A)}{\sigma_{m 22}} ; \stackrel{(B)}{\sigma_{m 33}}=\stackrel{(B)}{\sigma_{m 22} ;} \underset{\sigma_{f 33}}{(B)}=\frac{(B)}{\sigma_{f 22}}=\sigma_{m 22}^{(B)}$

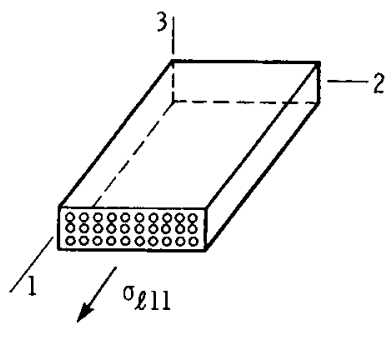

PLY MATERIAL AXES

Figure 7. - Ply microstresses - stresses in the constituents.

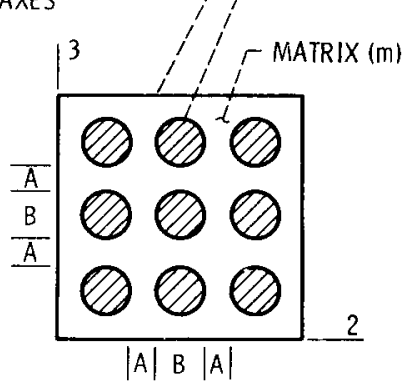

MICROSTRESS REGIONS

DUE TO TRANSVERSE LOAD $\left(\sigma_{\ell 22}\right)$

$$
\begin{aligned}
& \sigma_{m l l}=\left(v_{m}-\frac{v_{\ell 12} E_{m}}{E_{\ell 11}}\right) \sigma_{\ell 22} \\
& \sigma_{f 11}=\left(v_{f 12}-v_{\ell 12} \frac{E_{f 11}}{E_{\ell 11}}\right) \sigma_{\ell 22} \\
& { }_{m 22}^{(A)}=\left(E_{m} / E_{22}\right) \sigma_{\ell 22} \\
& \underset{m 22}{(B)}=\left(E_{\ell 22} / E_{22}\right)^{0} \ell 22 \\
& \sigma_{f 22}^{(B)}=\left(E_{\ell 22 / E_{22}}\right)^{\sigma} \ell 22 \\
& \sigma_{m 133}^{(A)}=\left(v_{m}-v_{\ell 23}\right)\left(E_{m} / E_{\ell 22}\right) \sigma_{\ell 22} \\
& \sigma_{m 33}^{(B)}=-\left(\frac{1-\sqrt{k_{f}}}{\sqrt{k_{f}}}\right) \sigma_{m 33}^{(A)} \\
& \underset{\sigma_{f 3}}{(B)}=-\left(\frac{1-\sqrt{k_{f}}}{\sqrt{k_{f}}}\right) \sigma_{m 33}^{(A)} \\
& \text { PLY MATERIAL AXES } \\
& \text { (l) } \\
& \text { MICROSTRESS REGIONS } \\
& E_{22}=\left(1-\sqrt{k_{f}}\right) E_{m}+\frac{\sqrt{k_{f}} E_{m}}{1-\sqrt{k_{f}}\left(1-\frac{E_{m}}{E_{f 22}}\right)} ; E_{\ell 22}=\frac{E_{m}}{1-\sqrt{k_{f}}\left(1-\frac{E_{m}}{E_{f 22}}\right)} \\
& v_{\ell 23}=k_{f} v_{f} 23+k_{m}\left(2 v_{m}-v_{\ell 12} E_{\ell 22 I^{E}}^{E} \ell 11\right)
\end{aligned}
$$

Figure 8. - Ply microstresses - stresses in the constituents. 
DUE TO INTRAPLY SHEAR STRESS $\left(\sigma_{\ell 12}\right)$

$\sigma_{m 12}^{(A)}=\left(G_{m} / G_{12}\right) \sigma_{\ell 12}$

$\stackrel{(B)}{\sigma_{m 12}}=\left(G_{\ell 12} / G_{12}\right) \sigma_{\ell 12}$

$\underset{\sigma_{f 12}}{(B)}=\left(G_{\ell 12} / G_{12}\right)_{\ell 12}$

$G_{12}=\left(1-\sqrt{k_{f}}\right) G_{m}+\frac{\sqrt{k_{f}} G_{m}}{1-\sqrt{k_{f}}\left(1-\frac{G_{m}}{G_{f 12}}\right)} ;$
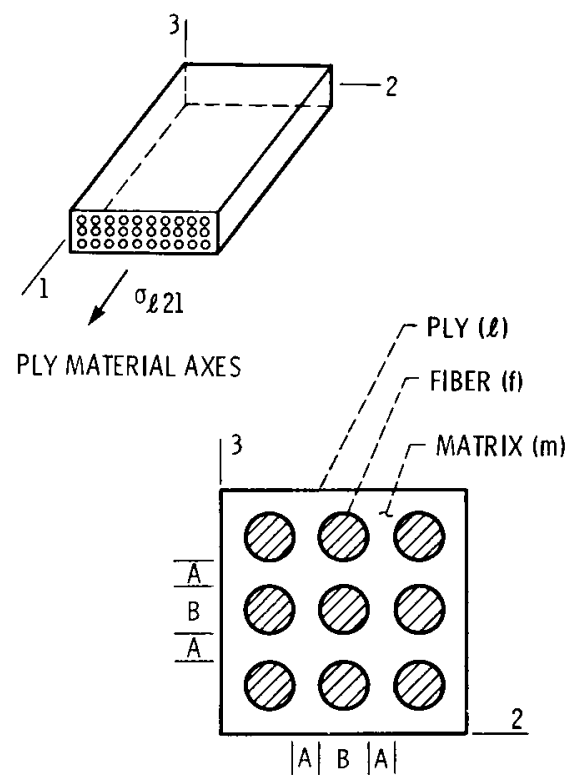

MICROSTRESS REGIONS

Figure 9. - Ply microstresses - stresses in the constituents.

CD-86-18688

DUE TO THROUGH-THE-THICKNESS SHEAR

$\begin{aligned}(A) & =\left(G_{m} / G_{\ell 23}\right) \sigma_{\ell 23} \\ \sigma_{m 23} & (B) \\ \sigma_{m 23} & =\left(G_{23} / G_{\ell 23}\right) \sigma_{\ell 23} \\ \sigma_{f 23} & =\sigma_{m 23}^{(B)}\end{aligned}$

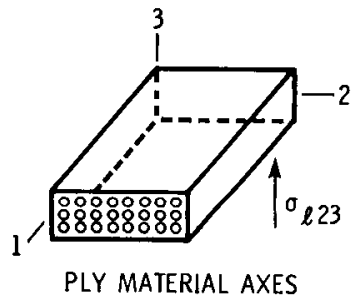

$G_{\ell 23}=\frac{G_{m}}{1-k_{f}\left(1-\frac{G_{m}}{G_{f 23}}\right)}$

$G_{23}=\frac{G_{m}}{1-\sqrt{k_{f}}\left(1-\frac{G_{m}}{G_{f 23}}\right)}$

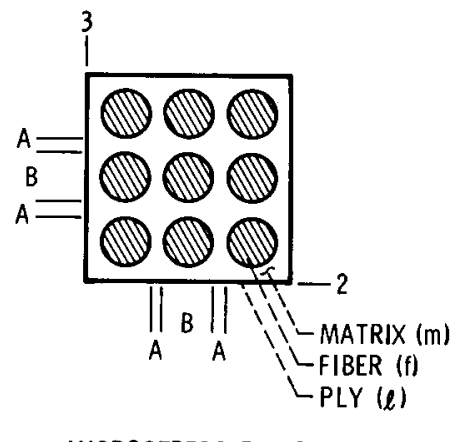

MICROSTRESS REGIONS

Figure 10. - Ply microstresses - stresses in the constituents. 
DUE TO TEMPERATURE $\left(\Delta \mathrm{T}_{\ell}\right)$

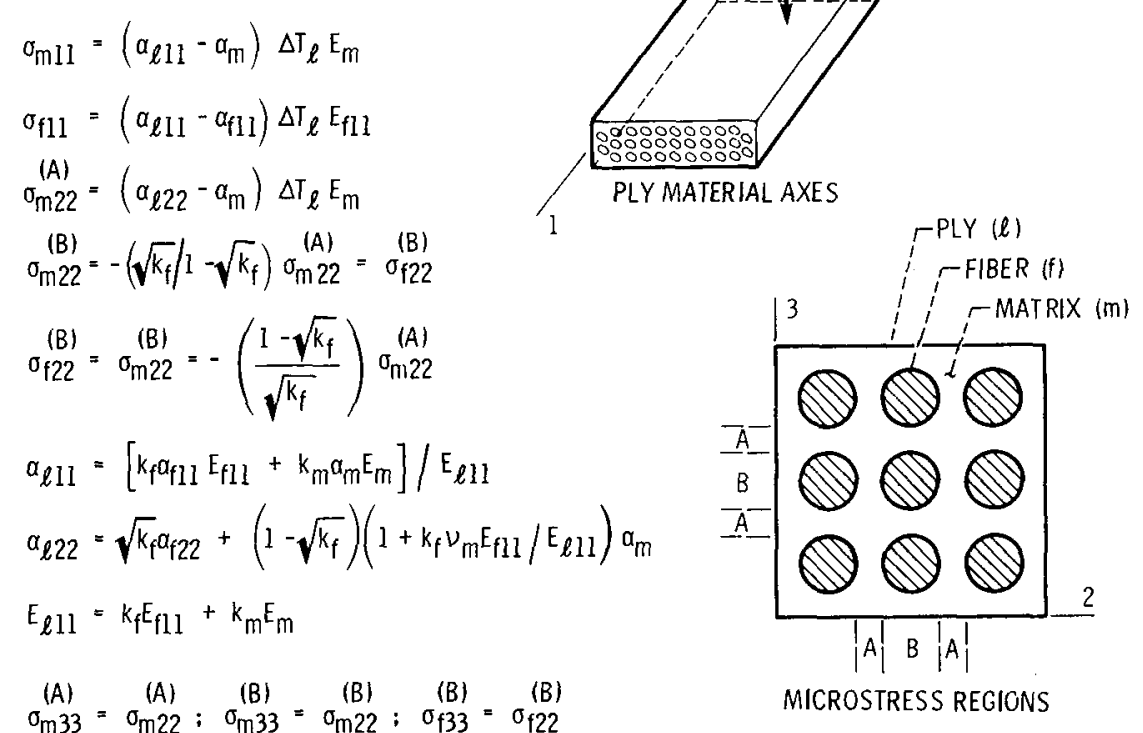

Figure 11. - Ply microstresses - stresses in the constituents.

DUE TO MOISTURE $\left(M_{\ell}\right)$

$$
\begin{aligned}
& \sigma_{m 11}=\left(\beta_{\ell 11}-\beta_{m}\right) M_{\ell} E_{m} \\
& \sigma_{f 11}=\beta_{\ell 11} M_{\ell} E_{f 11} \\
& \sigma_{m 22}^{(A)}=\left(\beta_{\ell 22}-\beta_{m}\right) M_{\ell} E_{m} \\
& \sigma_{f 22}^{(B)}=\sigma_{m 22}^{(B)}=-\left(\frac{1-\sqrt{k_{f}}}{\sqrt{k_{f}}}\right) \sigma_{m 22}^{(A)} \\
& \beta_{\ell 11}=\left(1-k_{f}\right) \beta_{m} E_{m} / E_{\ell 11} \\
& \beta_{\ell 22}=B_{m}^{\left(1-\sqrt{k_{f}}\right)}\left[1+\frac{\sqrt{k_{f}}\left(1-\sqrt{k_{f}}\right) E_{m}}{\sqrt{k_{f}} E_{\ell 22}+\left(1-\sqrt{k_{f}}\right) E_{m}}\right]=\beta_{\ell 33} \\
& E_{\ell 11}=k_{f} E_{f 11}+k_{m} E_{m} ; E_{\ell 22}=\frac{E_{m}}{1-\sqrt{k_{f}}\left(1-E_{m 1} / E_{f 22}\right)} \\
& \sigma_{m 33}^{(A)}=\sigma_{m 22}^{(A)} ; \quad \sigma_{m 33}^{(B)}=\sigma_{m 22}^{(B)} ; \quad \sigma_{f 33}^{(B)}=\sigma_{f 22}^{(B)}
\end{aligned}
$$
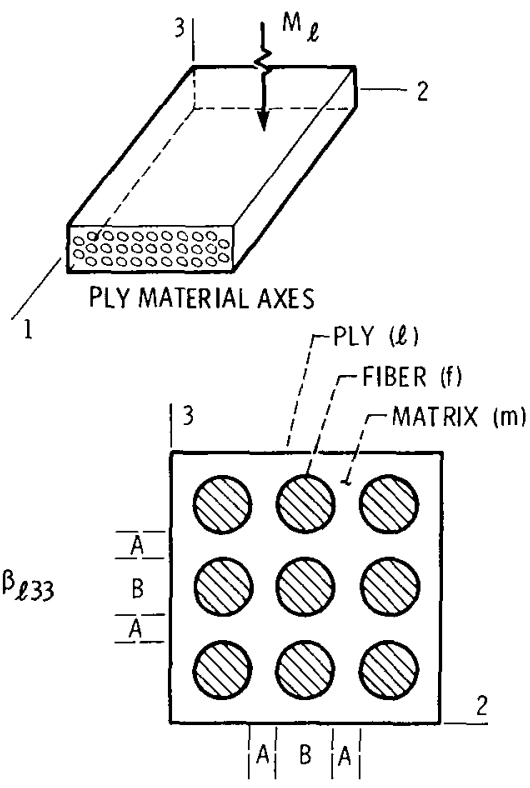

MICROSTRESS REGIONS

Figure 12. - Ply microstresses - stresses in constituents. 


\begin{tabular}{|c|c|c|}
\hline $\begin{array}{l}\text { 1. Report No. } \\
\text { NASA TM-87295 }\end{array}$ & 2. Government Accession No. & 3. Recipient's Catalog No. \\
\hline \multirow{4}{*}{\multicolumn{2}{|c|}{$\begin{array}{l}\text { 4. Title and Subtille } \\
\text { Simplified Composite Micromechanics for Predicting } \\
\text { Microstresses }\end{array}$}} & 5. Report Date \\
\hline & & \\
\hline & & 6. Performing Organization Code \\
\hline & & $505-63-11$ \\
\hline \multirow{3}{*}{\multicolumn{2}{|c|}{$\begin{array}{l}\text { 7. Author(s) } \\
\text { Christos C. Chamis }\end{array}$}} & 8. Performing Organization Report No. \\
\hline & & $E-2782$ \\
\hline & & 10. Work Unit No. \\
\hline \multirow{2}{*}{\multicolumn{2}{|c|}{$\begin{array}{l}\text { 9. Performing Organization Name and Address } \\
\text { National Aeronautics and Space Administration } \\
\text { Lewis Research Center } \\
\text { Cleveland, Ohio } 44135\end{array}$}} & \\
\hline & & 11. Contract or Grant No. \\
\hline \multicolumn{2}{|l|}{ 12. Sponsoring Agency Name and Address } & Technical Memorandum \\
\hline \multicolumn{2}{|l|}{$\begin{array}{l}\text { National Aeronautics and Space Administration } \\
\text { Washington, D.C. } 20546\end{array}$} & 14. Sponsoring Agency Code \\
\hline \multirow{2}{*}{\multicolumn{3}{|c|}{$\begin{array}{l}\text { 15. Supplementary Notes } \\
\text { Prepared for the } 41 \text { st Annual Conference of the Society of the Plastics Industry } \\
\text { (SPI) Reinforced Plastics/Composites Institute, Atlanta, Georgia, January } 27-31 \text {, } \\
\text { 1986. }\end{array}$}} \\
\hline & & \\
\hline \multirow{2}{*}{\multicolumn{3}{|c|}{$\begin{array}{l}\text { 16. Abstract } \\
\text { A unified set of composite micromechanics equations is summarized and described. } \\
\text { This unified set is for predicting the ply microstresses when the ply stresses } \\
\text { are known. The set consists of equations of simple form for predicting three- } \\
\text { dimensional stresses ( } 1 \text { ix each) in the matrix, fiber, and interface. Several } \\
\text { numerical examples are included to illustrate use and computational effectiveness } \\
\text { of the equations in this unified set. Numerical results from these examples are } \\
\text { discussed with respect to their significance on microcrack formation and, there- } \\
\text { fore, damage initiation in fiber composites. }\end{array}$}} \\
\hline & & \\
\hline $\begin{array}{l}\text { 17. Key Words (Suggested by Author(s)) } \\
\text { Fiber composite; Polymer matrices; Fiber stresses; } \\
\text { Matrix stresses; Interface stresses; Simplified } \\
\text { equations; Three-dimensional stresses; Mechanical- } \\
\text { load stresses; Thermal stresses; Hygral stresses; } \\
\text { Fracture stresses; Failure modes }\end{array}$ & \multicolumn{2}{|c|}{$\begin{array}{l}\text { 18. Distribution Statement } \\
\text { Unc lassified - unlimited } \\
\text { STAR Category } 24\end{array}$} \\
\hline $\begin{array}{l}\text { 19. Security Classif. (of this report) } \\
\text { Unc lass if led }\end{array}$ & $\begin{array}{l}\text { page) } \\
\text { sified }\end{array}$ & \begin{tabular}{|l|l|} 
21. No. of pages & 22. Price \\
\end{tabular} \\
\hline
\end{tabular}

